\title{
Predicting cardiometabolic disturbances from waist-to-height ratio: findings from the Brazilian Longitudinal Study of Adult Health (ELSA-Brasil) baseline
}

\author{
Marcelo Castanheira ${ }^{1, *}$, Dóra Chor ${ }^{2}$, José Uéleres Braga ${ }^{2,3}$, Letícia de Oliveira Cardoso ${ }^{2}$, \\ Rosane Härter Griep ${ }^{4}$, Maria del Carmen Bisi Molina ${ }^{5}$ and Maria de Jesus Mendes da \\ Fonseca $^{2}$ \\ 'Departamento de Nutrição Fundamental, Escola de Nutrição, Universidade Federal do Estado do Rio de Janeiro, \\ Av. Pasteur 296, 3rd floor - Urca, Rio de Janeiro, RJ, Brazil: ${ }^{2}$ Escola Nacional de Saúde Pública, Fundação \\ Oswaldo Cruz, Rio de Janeiro, RJ, Brazil: ${ }^{3}$ Instituto de Medicina Social, Universidade do Estado do Rio de Janeiro, \\ Rio de Janeiro, RJ, Brazil: ${ }^{4}$ Laboratório de Educação em Ambiente e Saúde, Instituto Oswaldo Cruz, Fundação \\ Oswaldo Cruz, Rio de Janeiro, RJ, Brazil: ${ }^{5}$ Centro de Ciências da Saúde, Universidade Federal do Espírito Santo, \\ Vitória, ES, Brazil
}

Submitted 14 December 2016: Final revision received 21 September 2017: Accepted 18 0ctober 2017: First published online 9 January 2018

\begin{abstract}
Objective: To evaluate the performance of waist-to-height ratio (WHtR) in predicting cardiometabolic outcomes and compare cut-off points for Brazilian adults.

Design: Cross-sectional study. WHtR areas under the curve (AUC) were compared with those for BMI, waist circumference (WC) and waist-to-hip ratio (WHR). The outcomes of interest were hypertension, diabetes, hypertriacylglycerolaemia and presence of at least two components of metabolic syndrome $(\geq 2$ MetS). Cut-offs for WHtR were compared and validity measures were estimated for each point.

Setting: Teaching and research institutions in six Brazilian state capitals, 2008-2010. Subjects: Women ( $n$ 5026) and men ( $n$ 4238) aged $35-54$ years who participated in the Brazilian Longitudinal Study of Adult Health (ELSA-Brasil) at baseline. Results: WHtR age-adjusted AUC ranged from 0.68 to 0.72 in men and 0.69 to 0.75 in women, with smaller AUC for hypertriacylglycerolaemia and the largest for $\geq 2$ MetS. WHtR performed better than BMI for practically all outcomes; better than WHR for hypertension in both sexes; and displayed larger AUC than WC in predicting diabetes mellitus. It also offered better discriminatory power for $\geq 2$ MetS in men; and was better than WC, but not WHR, in women. Optimal cut-off points of WHtR were 0.55 (women) and 0.54 (men), but they presented high falsenegative rate compared with $0 \cdot 50$.

Conclusions: We recommend using WHtR (which performed similarly to, or better than, other available indices of adiposity) as an anthropometric index with good discriminatory power for cardiometabolic outcomes in Brazilian adults, indicating the already referenced limit of WHtR $\geq 0 \cdot 50$.
\end{abstract}

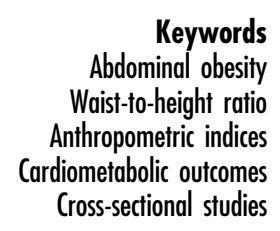

Chronic non-communicable diseases are the leading cause of mortality in numerous countries and various strategies to address them have been discussed ${ }^{(1)}$. One of the main avenues is to combat obesity, in which abdominal obesity, the type most strongly associated with such diseases, has received attention from researchers owing to the greater accuracy it offers in detecting increased visceral fat, which is implicated in cardiometabolic alterations ${ }^{(2)}$.

Traditionally, abdominal obesity has been gauged by way of waist circumference (WC), either in isolation or as a ratio to hip circumference (waist-to-hip ratio, WHR) ${ }^{(3)}$.
However, given the more important inverse relationship between height and cardiometabolic disturbances ${ }^{(4-6)}$, several authors have suggested adjusting WC for height to augment its diagnostic power in comparison with other anthropometric indices for abdominal and total adiposity $^{(7-9)}$. In Brazil, waist-to-height ratio (WHtR) is being indicated as a good predictor for arterial hyperten$\operatorname{sion}^{(10,11)}$ and coronary risk ${ }^{(12,13)}$.

Some studies, however, have found in favour of using $\mathrm{BMI}^{(14)}$ and $\mathrm{WC}^{(15)}$, as well as $\mathrm{WHR}^{(16)}$, for different cardiometabolic outcomes. 
Given the lack of consensus on the measure most indicated for evaluating abdominal obesity in adults, the present study aimed to answer the following questions: with what likelihood does WHtR correctly identify adult individuals with cardiometabolic alterations? Does this index offer better discriminatory power than other measures of abdominal obesity in detecting clinical outcomes in this age group? Considering the population of the Brazilian Longitudinal Study of Adult Health (ELSA-Brasil), what is the optimal cut-off point of WHtR for predicting these outcomes? Does it perform better than the main cutoff point referenced in the literature $(0.50)$ ?

\section{Participants and methods}

The present cross-sectional study draws on the ELSA-Brasil baseline, the methodological details of which have been described elsewhere ${ }^{(17,18)}$. To summarise, the population eligible for ELSA-Brasil comprised active and retired civil servants, aged 35-74 years, from teaching and research institutions in six Brazilian state capitals (Porto Alegre, São Paulo, Rio de Janeiro, Vitória, Salvador and Belo Horizonte).

For the present study, a population aged 35-54 years was selected to gain greater age group homogeneity and in view of the low predictive power of anthropometric indices with increasing age. Individuals lacking information on any of the anthropometric measures of interest ( $n$ 6) or on biochemical variables $(n 8)$ were excluded; no values were missing for blood pressure. Participants thus totalled 9264, 4238 men and 5026 women.

\section{Data collection procedures}

At the ELSA-Brasil baseline (2008-2010), data were collected by a trained team using standardised procedures and equipment at all the ELSA-Brasil study centres ${ }^{(19)}$.

The anthropometric measures of weight, height and waist and hip circumferences were obtained using techniques recommended by Lohman et al. ${ }^{(20)}$, each measurement being taken only once. WC was measured at the mid-point between the lower edge of the costal arch and the iliac crest at the mid-axillary line.

Three measurements of blood pressure (BP) were taken, with the mean of the last two being used in the analyses $^{(21)}$.

As part of the quality control procedures, some measurements were repeated randomly in a study sub-sample. A high intraclass correlation coefficient was found for WC (0.99), for systolic BP (0.88) and for diastolic BP (0.89), indicating good reliability in taking these measurements and thus in constructing the indicators derived from them ${ }^{(19)}$.

The following biochemical blood measurements were used in defining the clinical indicators: glucose $(\mathrm{mg} / \mathrm{dl})$, TAG $(\mathrm{mg} / \mathrm{dl})$ and HDL cholesterol $(\mathrm{mg} / \mathrm{dl})$. Laboratory samples were collected from participants after a $12 \mathrm{~h}$ overnight fast ${ }^{(22)}$.

\section{Antbropometric predictors}

The anthropometric indices tested were: (i) BMI $\left(\mathrm{kg} / \mathrm{m}^{2}\right)$; (ii) WC (cm); (iii) WHR; and (iv) WHtR.

\section{Cardiometabolic outcomes}

Blood pressure and blood biochemistry served to construct the following selected cardiometabolic outcomes, which were treated dichotomously (yes/no): (i) hypertension, classified as systolic BP $\geq 140 \mathrm{mmHg}$ and/or diastolic $\mathrm{BP} \geq 90 \mathrm{mmHg}$ and/or use of antihypertensive medication during the two weeks prior to the test; (ii) hypertriacylglycerolaemia, TAG $\geq 150 \mathrm{mg} / \mathrm{dl}$; and (iii) diabetes mellitus, reported as prior clinical diagnosis and/or use of medication and/or fasting glycaemia $>125 \mathrm{mg} / \mathrm{dl}$ and/or $2 \mathrm{~h}$ post-test glycaemia $\geq 200 \mathrm{mg} / \mathrm{dl}$ in an oral glucose tolerance test.

The last outcome investigated was the presence of two or more components of metabolic syndrome ( $\geq 2$ MetS), out of a total four possible components: (i) BP $\geq 130$ and/ or $85 \mathrm{mmHg}$; (ii) $\mathrm{TAG} \geq 150 \mathrm{mg} / \mathrm{dl}$; (iii) HDL cholesterol $<40 \mathrm{mg} / \mathrm{dl}$ (men) or $<50 \mathrm{mg} / \mathrm{dl}$ (women); (iv) fasting glycaemia $\geq 110 \mathrm{mg} / \mathrm{dl}$; these limits are based on the National Cholesterol Education Program Adult Treatment Panel III $^{(23)}$. WC was excluded in this case, because its presence could lead to collinearity with the indicators used to evaluate abdominal fat, which also include waist measurement. The use of two or more positive components of metabolic syndrome is a diagnostic option already successfully employed by other authors ${ }^{(5,14,24)}$. It is at least as frequent a condition as the situations in isolation - if not more so - and, more importantly still, this set of components of metabolic syndrome together is of greater clinical significance.

\section{Data analysis}

The area under the receiver-operator characteristic curve (AUC) and the respective 95\% confidence intervals were calculated, for men and women, for each pair of anthropometric index (BMI, WC, WHR and WHtR) and metabolic outcome of interest (hypertension, diabetes, hypertriacylglycerolaemia and $\geq 2$ MetS). Then, the differences between WHtR AUC and that for each age-adjusted anthropometric index were tested ${ }^{(25)}$. AUC are summary measures of the performance of a predictive model. The larger the value of the AUC for a given outcome, the greater the model's power of discrimination. The value $1 \cdot 0$ indicates excellent power to discriminate between the presence or absence of the outcome and 0.5 is the limit of significance. Accordingly, the lower limit of the $95 \%$ CI should not be below $0 \cdot 5^{(26,27)}$.

The cut-off points recommended in the literature for the study indices were examined for sensitivity and specificity in detecting two or more metabolic syndrome components, that is: (i) BMI $\geq 25 \cdot 0 \mathrm{~kg} / \mathrm{m}^{2}$ and $\geq 30 \cdot 0 \mathrm{~kg} / \mathrm{m}^{2}$, for either sex ${ }^{(28)}$; (ii) $\mathrm{WC} \geq 88 \mathrm{~cm} \quad(\mathrm{men})^{(28)}$ and $\geq 102 \mathrm{~cm}$ (women) $^{(28)}$; (iii) $\mathrm{WHR} \geq 0 \cdot 80^{(16)}$ or $\geq 0 \cdot 85^{(28)}$ (women) 
and $\geq 0.90^{(28)}$ or $\geq 0.95^{(16)}$ (men); and (iv) WHtR $\geq 0.50$ and $\geq 0 \cdot 60$, for either sex ${ }^{(29)}$.

The next stage was to obtain optimal cut-off points for each anthropometric index, using two strategies. The first was to calculate the Youden index $(J)=\max$ (sensitivity + specificity - 1), from which the point vertically furthest from the non-association AUC was identified; then, the cut-off point representing the least distance squared $\left(d^{2}\right)$ between the receiver-operator characteristic curve and the point closest to the ideal, represented by the upper left-hand corner of the AUC plot, which indicates maximum accuracy ${ }^{(30)}$.

A more detailed analysis was made of the predictive power of two different cut-off points of WHtR: $\geq 0.50$, for either sex ${ }^{(29)}$, and that identified in the previous analysis. The calculated statistics included sensitivity, specificity, false-positive rate, false-negative rate, test accuracy and Brier score, stratified by sex and age group.

The Brier score represents an overall measure of the model's performance and evaluates the distance between the likelihood predicted by the index in test (in this case WHtR) and the likelihood of the outcome occurring. A value of $0 \%$ agrees totally and the nearer values approach $50 \%$, the worse the model's performance and, therefore, the less informative it is - at $50 \%$ it offers the same probability of being right or wrong. Above $50 \%$ it has no clinical significance. This score penalises false positives and false negatives less than $R^{2}$ does ${ }^{(27)}$.

Lastly, the OR and respective $95 \% \mathrm{CI}$ values were calculated between the high WHtR (classified by the different cut-off points identified) and the $\geq 2$ MetS outcome.

The data were analysed using the statistical software packages MedCalc ${ }^{\circledR}$ version 14.1 and Stata ${ }^{\circledR}$ version 10.1.

All participants signed a declaration of free and informed consent. The present paper is the product of a subproject approved by the Ethics Committee of Brazil's Escola Nacional de Saúde Pública (CAAE No. 44106915.2.1001.5240).

\section{Results}

Women made up $54 \%$ of the study population. Mean age (46.2 (SD 5.1) years; $P=0.18$ ) was similar in both sexes, with nearly one-third of the population in each age stratum, as shown in Table 1. Table 1 also shows that mean WC and WHR were, as expected, higher in men, while BMI and WHtR (indices formulated to include height) did not differ between the sexes. All indices relating to adiposity increased linearly with age in both sexes. The increase was more marked in measures of abdominal obesity (WC, WHR and WHtR) than in BMI. In all age groups, the prevalence of the clinical outcomes was greater among men, and the outcome $\geq 2$ MetS was twice as prevalent in men as in women.

The values of the WHtR AUC, after adjustment for age, can be seen in Table 2 . They ranged from 0.68 to 0.72 in

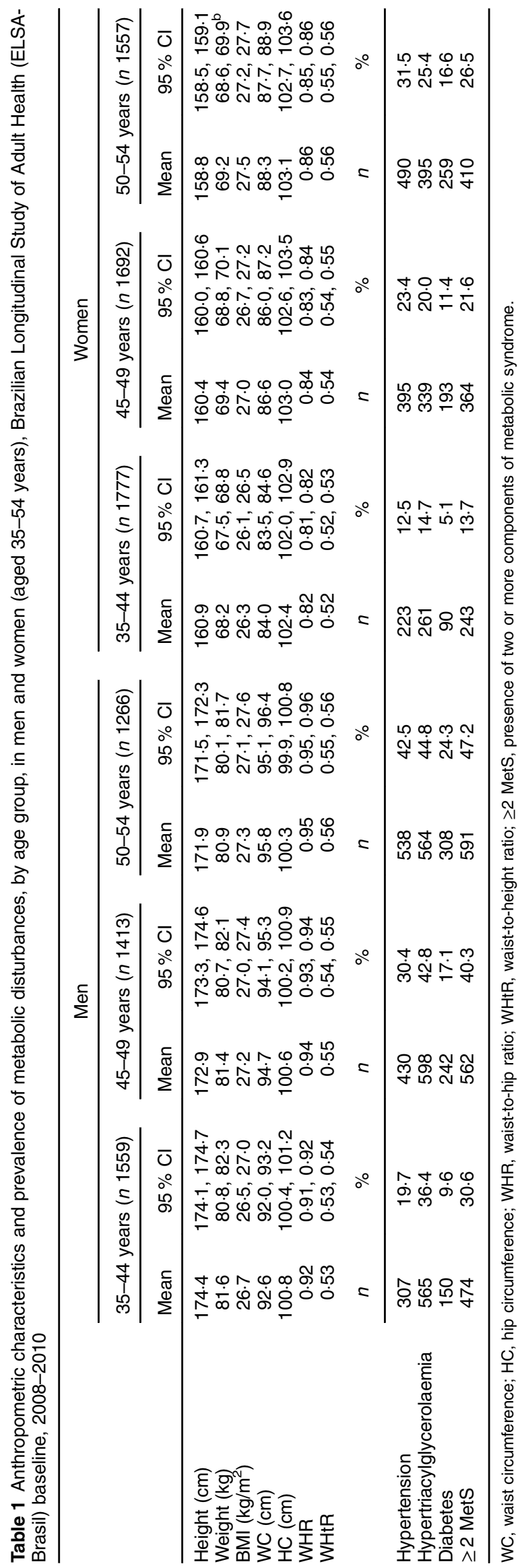


Table 2 Adjusted $\dagger$ area under the curve (AUC) and respective $95 \% \mathrm{Cl}$ for anthropometric predictors of metabolic disturbances in men and women (aged 35-54 years), Brazilian Longitudinal Study of Adult Health (ELSA-Brasil) baseline, 2008-2010

\begin{tabular}{|c|c|c|c|c|c|c|c|c|}
\hline \multirow[b]{2}{*}{ Anthropometric index } & \multicolumn{2}{|c|}{ Hypertension } & \multicolumn{2}{|c|}{ Hypertriacyglycerolaemia } & \multicolumn{2}{|c|}{ Diabetes } & \multicolumn{2}{|c|}{$\geq 2$ MetS } \\
\hline & AUC & $95 \% \mathrm{Cl}$ & AUC & $95 \% \mathrm{Cl}$ & AUC & $95 \% \mathrm{Cl}$ & AUC & $95 \% \mathrm{Cl}$ \\
\hline Men & \multicolumn{2}{|c|}{$n 4234$} & \multicolumn{2}{|c|}{$n 4210$} & \multicolumn{2}{|c|}{$n 4236$} & \multicolumn{2}{|c|}{ n 4194} \\
\hline BMI $\left(\mathrm{kg} / \mathrm{m}^{2}\right)$ & 0.689 & $0.670,0.706$ & $0.665^{\star \star \star}$ & $0.649,0.682$ & $0.668^{\star * \star}$ & $0.645,0.691$ & $0.709^{\star \star}$ & $0.692,0.725$ \\
\hline WC (cm) & 0.683 & $0.664,0.701$ & 0.679 & $0.664,0.695$ & $0.664^{\star * *}$ & $0.641,0.687$ & $0.707^{\star \star}$ & $0.690,0.724$ \\
\hline WHR & $0.659^{\star * *}$ & $0.641,0.677$ & 0.687 & $0.670,0.703$ & 0.680 & $0.659,0.702$ & $0.705^{\star *}$ & $0.689,0.721$ \\
\hline WHtR & 0.689 & $0.671,0.707$ & 0.683 & $0.667,0.700$ & 0.689 & $0.667,0.711$ & 0.720 & $0.704,0.736$ \\
\hline Women & \multicolumn{2}{|c|}{ n 5025} & \multicolumn{2}{|c|}{$n 5022$} & \multicolumn{2}{|c|}{$n 5026$} & \multicolumn{2}{|c|}{$n 5004$} \\
\hline BMI $\left(\mathrm{kg} / \mathrm{m}^{2}\right)$ & $0.679^{\star \star}$ & $0.661,0.698$ & $0.668^{\star \star \star}$ & $0.650,0.686$ & $0.711^{\star * *}$ & $0.688,0.734$ & $0.728^{\star \star \star}$ & $0.711,0.745$ \\
\hline WC $(\mathrm{cm})$ & 0.688 & $0.670,0.705$ & 0.691 & $0.674,0.708$ & $0.722^{*}$ & $0.699,0.744$ & $0.745^{\star \star}$ & $0.729,0.761$ \\
\hline WHR & $0.674^{\star *}$ & $0.656,0.692$ & 0.708 & $0.691,0.726$ & 0.726 & $0.704,0.749$ & 0.749 & $0.733,0.766$ \\
\hline WHtR & 0.693 & $0.675,0.711$ & 0.694 & $0.677,0.711$ & 0.730 & $0.708,0.753$ & 0.754 & $0.738,0.770$ \\
\hline
\end{tabular}

WC, waist circumference; WHR, waist-to-hip ratio; WHtR, waist-to-height ratio; $\geq 2$ MetS, presence of two or more components of metabolic syndrome. ${ }^{\star} P<0.05,{ }^{* *} P<0.01,{ }^{* \star *} P<0.001$ in test to differentiate between two AUC (WHtR $v$. other anthropometric indices).

†Adjusted for age group.

Table 3 Reference and optimal† cut-off points for selected anthropometric indices applied in discriminating the presence of two or more components of metabolic syndrome in men and women (aged 35-54 years), Brazilian Longitudinal Study of Adult Health (ELSA-Brasil) baseline, 2008-2010

\begin{tabular}{|c|c|c|c|c|c|c|c|c|}
\hline \multirow[b]{3}{*}{ Anthropometric index } & \multicolumn{8}{|c|}{ Cut-off points } \\
\hline & \multicolumn{4}{|c|}{ Men ( $n$ 4194) } & \multicolumn{4}{|c|}{ Women (n 5004) } \\
\hline & Reference & Reference & $J$ & $d^{2}$ & Reference & Reference & $J$ & $d^{2}$ \\
\hline \multicolumn{9}{|l|}{ BMI $\left(\mathrm{kg} / \mathrm{m}^{2}\right)$} \\
\hline Cut-off point & $25 \cdot 0^{(28)}$ & $30 \cdot 0^{(28)}$ & $26 \cdot 3$ & $27 \cdot 0$ & $25 \cdot 0^{(28)}$ & $30 \cdot 0^{(28)}$ & $27 \cdot 0$ & $27 \cdot 1$ \\
\hline Sensitivity (\%) & 83.8 & $35 \cdot 2$ & 71.8 & 64.5 & 83.6 & $46 \cdot 6$ & $71 \cdot 2$ & $70 \cdot 4$ \\
\hline Specificity (\%) & $44 \cdot 3$ & $86 \cdot 8$ & 59.4 & $66 \cdot 5$ & 47.4 & $82 \cdot 3$ & $65 \cdot 1$ & $65 \cdot 8$ \\
\hline \multicolumn{9}{|l|}{$\mathrm{WC}(\mathrm{cm})$} \\
\hline Cut-off point & $94 \cdot 0^{(28)}$ & $102 \cdot 0^{(28)}$ & $92 \cdot 1$ & 93.1 & $80 \cdot 0^{(28)}$ & $88 \cdot 0^{(28)}$ & 88.3 & 88.3 \\
\hline Sensitivity (\%) & $67 \cdot 7$ & $36 \cdot 8$ & $74 \cdot 4$ & 70.5 & 91.0 & $69 \cdot 2$ & 68.8 & 68.9 \\
\hline Specificity (\%) & 63.0 & $86 \cdot 0$ & $57 \cdot 3$ & $61 \cdot 0$ & 39.4 & $69 \cdot 1$ & 69.9 & 69.7 \\
\hline \multicolumn{9}{|l|}{ WHR } \\
\hline Cut-off point & $0.90^{(28)}$ & $0.95^{(16)}$ & 0.92 & 0.94 & $0.80^{(16)}$ & $0.85^{(28)}$ & 0.85 & 0.85 \\
\hline Sensitivity (\%) & $87 \cdot 0$ & 58.0 & 76.0 & $67 \cdot 1$ & $91 \cdot 1$ & $72 \cdot 0$ & 71.9 & $71 \cdot 3$ \\
\hline Specificity (\%) & 41.5 & $72 \cdot 0$ & $56 \cdot 8$ & 64.8 & $37 \cdot 2$ & 67.6 & 67.9 & 68.5 \\
\hline \multicolumn{9}{|l|}{ WHtR } \\
\hline Cut-off point & $0.50^{(29)}$ & $0.60^{(29)}$ & 0.53 & 0.54 & $0.50^{(29)}$ & $0.60^{(29)}$ & 0.55 & 0.55 \\
\hline Sensitivity (\%) & 91.0 & $31 \cdot 7$ & 82.7 & 72.4 & $90 \cdot 7$ & 43.8 & 71.0 & $70 \cdot 2$ \\
\hline Specificity (\%) & $35 \cdot 8$ & $89 \cdot 0$ & 51.9 & $61 \cdot 3$ & 39.6 & 86.0 & $70 \cdot 0$ & $70 \cdot 7$ \\
\hline
\end{tabular}

WC, waist circumference; WHR, waist-to-hip ratio; WHtR, waist-to-height ratio.

†Optimal cut-off points corresponding to maximum value of the Youden index $(J)=\max ($ sensitivity + specificity -1$)$ or the least distance squared $\left(d^{2}\right)$ between the receiver-operating characteristic curve and the upper left-hand corner of the AUC plot.

men and from 0.69 to 0.75 in women, with the smallest AUC found for hypertriacylglycerolaemia and the largest for $\geq 2$ MetS. The AUC obtained for WHtR were also compared with those of the other anthropometric indices for each clinical outcome. WHtR returned significantly larger AUC than BMI for practically all outcomes examined, except hypertension among men. WHtR performed significantly better than WHR for hypertension in both sexes and also displayed larger AUC than WC in predicting diabetes. When the $\geq 2$ MetS outcome was examined, WHtR showed better discriminatory power than the other indices, although not differing from WHR in women (Table 2).

The analysis stratified by age group (data not shown) showed that, for all the anthropometric indices tested, AUC values diminished with age. However, loss of predictive power was greater for men after 50 years of age. WHtR maintained reasonably informative AUC values, i.e. good predictive power, in all age strata, with values greater than 0.69 for men and 0.74 for women (from age 50 to 54 years). Among women, WHtR and WHR performed equally well after age 50 years, while WC and BMI showed a more marked decline.

Sensitivity and specificity values at different cut-off points for the anthropometric indices were compared for the $\geq 2$ MetS outcome (Table 3 ). Many of the cut-off points observed in our study were higher than those previously identified in the literature. The exceptions to this were WC in men and, in some cases, WC and WHR in women.

To evaluate discriminatory characteristics, validity measures were calculated for the classic cut-off of WHtR 
Table 4 Validity measures of waist-to-height ratio (WHtR) cut-off points and OR and $95 \% \mathrm{Cl}$ for presence of two or more components of metabolic syndrome ( $\geq 2$ MetS), by sex and age, Brazilian Longitudinal Study of Adult Health (ELSA-Brasil) baseline, 2008-2010

\begin{tabular}{|c|c|c|c|c|c|c|c|c|c|}
\hline \multirow[b]{2}{*}{ Categories } & \multicolumn{6}{|c|}{ Validity measures of WHtR cut-off points } & \multicolumn{3}{|c|}{$\geq 2$ MetS } \\
\hline & SENS (\%) & SPEC (\%) & FPR $(\%)$ & FNR (\%) & Accuracy (\%) & Brier score & $\begin{array}{c}\% \text { within } \\
\text { WHtR } \geq 0.50\end{array}$ & OR & $95 \% \mathrm{Cl}$ \\
\hline \multicolumn{10}{|c|}{ Men aged 35-49 years ( $n$ 2942) } \\
\hline WHtR $\geq 0.50$ & $90 \cdot 0$ & 38.4 & $61 \cdot 6$ & $10 \cdot 0$ & $56 \cdot 5$ & 0.43 & $44 \cdot 2$ & $5 \cdot 6$ & $4.5,7 \cdot 0$ \\
\hline $\mathrm{WHtR} \geq 0.54$ & $70 \cdot 0$ & $64 \cdot 7$ & $35 \cdot 3$ & $30 \cdot 4$ & $66 \cdot 4$ & 0.33 & $52 \cdot 0$ & $4 \cdot 2$ & $3 \cdot 6,4.9$ \\
\hline \multicolumn{10}{|c|}{ Men aged $50-54$ years $(n 1252)$} \\
\hline $\mathrm{WH} t \mathrm{R} \geq 0.50$ & 93.1 & 28.4 & 71.6 & 6.9 & 58.9 & 0.42 & $53 \cdot 8$ & $5 \cdot 3$ & $3 \cdot 7,7 \cdot 6$ \\
\hline $\mathrm{WHtR} \geq 0.54$ & 74.0 & $54 \cdot 0$ & $46 \cdot 0$ & $26 \cdot 1$ & 63.4 & 0.36 & 59.0 & $3 \cdot 3$ & $2 \cdot 6,4 \cdot 2$ \\
\hline \multicolumn{10}{|c|}{ Women aged 35-49 years ( $n 3455)$} \\
\hline $\mathrm{WH} \mathrm{tR} \geq 0.50$ & $90 \cdot 0$ & 44.1 & 55.9 & $10 \cdot 0$ & $52 \cdot 2$ & 0.48 & 25.5 & $7 \cdot 1$ & $5 \cdot 4,9 \cdot 3$ \\
\hline WHtR $\geq 0.55$ & $69 \cdot 0$ & 71.6 & 28.4 & $31 \cdot 0$ & $71 \cdot 1$ & 0.28 & $34 \cdot 1$ & $5 \cdot 6$ & $4.7,6 \cdot 8$ \\
\hline \multicolumn{10}{|c|}{ Women aged $50-54$ years $(n 1549)$} \\
\hline $\mathrm{WHtR} \geq 0.50$ & 91.7 & 28.4 & 71.6 & 8.3 & $45 \cdot 2$ & 0.55 & 31.6 & 4.4 & $3 \cdot 0,6 \cdot 4$ \\
\hline$W H t R \geq 0.55$ & $75 \cdot 4$ & $61 \cdot 2$ & 38.8 & $24 \cdot 6$ & $65 \cdot 0$ & 0.35 & $41 \cdot 1$ & 4.8 & $3 \cdot 7,6 \cdot 2$ \\
\hline
\end{tabular}

SENS, sensitivity; SPEC, specificity; FPR, false-positive rate; FNR, false-negative rate; \% within WHtR $\geq 0.50$, prevalence of two or more components of metabolic syndrome in subjects with $W H t R \geq 0.50$.

$(\geq 0 \cdot 50)$ and the optimal cut-off points identified ( $\geq 0.54$ for men and $\geq 0.55$ for women), as shown in Table 4 . The first cut-off achieved greater sensitivity, with substantial falsepositive rate and higher Brier score.

\section{Discussion}

WHtR showed good predictive power to identify metabolic disturbances in isolation or jointly, returning AUC close to or greater than 0.70 for all the outcomes, particularly for predicting the presence of two or more components of metabolic syndrome ( $\geq 2 \mathrm{MetS})$.

In the present study, the WHtR AUC ranged from 0.68 to 0.72 in men and from 0.69 to 0.75 in women. AUC equal to or greater than 0.7 were identified in meta-analyses by Browning et $a l .{ }^{(31)}$ and Ashwell et $a l .{ }^{(8)}$, highlighting diabetes and metabolic syndrome.

For the same outcomes, similar WHtR AUC were observed for Iranian men ( 0.65 to 0.72$)$, but were lower for Iranian women (0.63 to 0.69$)$, with higher values for $\geq 2$ MetS in both sexes ${ }^{(32)}$. Studies have also found smaller AUC values for these same disturbances in China, ranging from 0.57 to 0.67 for men and from 0.60 to 0.67 for women $^{(14)}$. In Turkey, findings were similar to those of the present study for the different outcomes examined, especially regarding the $\geq 2$ MetS outcome, returning AUC of 0.70 and 0.76 , respectively, for men and women ${ }^{(24)}$.

Few studies in Brazil have used receiver-operator characteristic curves to measure and compare the performance of WHtR with other anthropometric indices ${ }^{(11-14)}$. Even using other outcomes, studies in Bahia State to identify coronary risk using the Framingham score found important WHtR AUC values for men $(0 \cdot 76)^{(12)}$ and women $(0.74)^{(13)}$. Vasques et al. ${ }^{(15)}$ examined insulin resistance in male workers at a public university in Minas Gerais and found a WHtR AUC of 0.70 . In Alagoas, in a female population-based study, Caminha et al. ${ }^{(11)}$ observed AUC equal to 0.73 when evaluating hypertension. Despite the different outcomes and populations, there are similarities in the values encountered for AUC, attesting to the predictive power of the WHtR indicator.

WHtR performed better than the other anthropometric indices, although not differing substantially from WHR for women.

WHtR performed better than BMI for practically all outcomes examined, in both men and women, which is corroborated by the meta-analyses of Lee et al. ${ }^{(7)}$, Ashwell et $a l^{(8)}$ and Savva ${ }^{(9)}$. The use of WC instead of weight to construct the indicator (WHtR) brings gains for identifying individuals with higher levels of abdominal fat, despite normal BMI levels ${ }^{(33)}$. It is widely recognised that the strongest association is between visceral fat and chronic diseases, compared with overweight ${ }^{(2,3)}$. In addition, it is advantageous to use two rather than three measures, and only one anthropometric indicator for the evaluation of obesity in the adult population, rather than BMI and waist, separately.

In men, WHtR was observed to outperform the other anthropometric indices in predictive power, although the differences from WC and WHR were less substantial in women. The expected presence of increased body fat in women's thighs and buttocks makes WHR also an important tool in evaluating the extent of body fat in women.

Using the same outcome ( $\geq 2$ MetS), Mirmiran et al. ${ }^{(32)}$ found higher AUC for WHtR compared with other anthropometric indices. Similarly, in Turkey, WHtR achieved the best discriminatory power in adults of both sexes, always better than $\mathrm{WHR}^{(24)}$.

The predictive power of anthropometric indices generally declines with age, which can be explained by the alterations in body composition that take place in both 
sexes. Among the women particularly, onset of menopause entails lower oestrogen production and increased abdominal adiposity as compared with the hip region ${ }^{(2)}$. The rather insignificant alterations in hip circumference measurements with advancing age found among participants in the ELSA-Brasil study point to a certain maintenance of subcutaneous adipose tissue, which is associated with lesser cardiovascular risk than intraabdominal or visceral adipose tissue ${ }^{(34)}$. That fact may explain why WHR was just as valid as WHtR in predicting cardiometabolic outcomes in women even after age 50 years, with both indicators managing to predict the occurrence of $\geq 2$ MetS accurately. Nevertheless, height would have the advantage, in addition to being selfreported, of being a more routine measurement in health research and services and less inconvenient for the individual examined.

It is noteworthy that ethnic differences among populations have more direct implications for WC, which shows quite different cut-off points by sex and ethnicity ${ }^{(35)}$. In this case, WHtR offers the advantage of having very close or identical cut-off points for men and women.

The choice of a cut-off point should be based more on the objectives of health care, than on statistical criteria, properly. The optimal cut-off points originating from the ELSA-Brasil population differed from those suggested by the literature, particularly for $\mathrm{BMI}^{(28)}$ and $\mathrm{WHtR}^{(31)}$. The latter points were established based on the balance between sensitivity and specificity, resulting in 0.55 for females and 0.54 for males.

In Brazil, these values had already been identified by Almeida et al. $^{(13)}$ to discriminate high coronary risk in women, with sensitivity and specificity of 68 and $66 \%$, respectively. For this same outcome, Haun et al. ${ }^{(12)}$ suggested slightly lower cut-off points ( 0.52 for men and 0.53 for women), and classified individuals with $68 \%$ sensitivity in both sexes and specificity of $64 \%$ for men and $58 \%$ for women. Caminha et al. ${ }^{(11)}$ found the optimal cut-off equal to 0.54 for women in Alagoas State.

For the same outcome ( $\geq 2$ MetS), suggested cut-off points vary considerably for different populations. In the population of $\operatorname{Iran}^{(32)}$, the cut-off point for men coincides with the finding of the present study $(0.54)$, but is much higher for women $(0 \cdot 59)$, due to high prevalence of female obesity. In China, where BMI measurements are around $23.0 \mathrm{~kg} / \mathrm{m}^{2}$, the cut-off points are 0.51 (men) and 0.53 (women) ${ }^{(14)}$; in Turkey, where mean BMI levels are high $\left(28.3 \mathrm{~kg} / \mathrm{m}^{2}\right.$ for men and $30.2 \mathrm{~kg} / \mathrm{m}^{2}$ for women), the proposed cut-offs are 0.58 and 0.59 , respectively ${ }^{(36)}$. And in the USA, Bohr et al. ${ }^{(37)}$ proposed the cut-off point of 0.58 to predict metabolic syndrome in young American adults (24 to 34 years).

High mean BMI and WC, in both sexes, were observed in ELSA-Brasil, which explains the higher optimal cut-off points of WHtR identified, since these indices are highly correlated, but with different predictive ability.
In present study, the cut-off for WHtR proposed internationally for both sexes ${ }^{(29,31)}(0 \cdot 50)$ obtained high sensitivity (about $90 \%$ ). When applied in populations with high prevalence of obesity (as in the case of ELSA-Brasil ${ }^{(18)}$ ), more sensitive cut-off points inflate the number of false positives. However, this is not a problem for actions in public health, in which we are interested in the early detection of individuals at risk or in subclinical stages of diabetes or CVD, like impaired glucose tolerance or dyslipidaemia. (Higher WHtR cut-off points reduced the prevalence of abdominal obesity in the population, in some strata by almost half - as among women up to 50 years of age - increasing by three or four times the number of false negatives, failing to detect a possible onset of metabolic disease.)

Therefore, the poor specificity presented by the 0.50 cut-off point does not compromise its use, since the cost the health care of these diseases will probably be much higher than the inclusion of false-positive individuals in new screening tests, such as BP measurement and laboratory tests ${ }^{(38)}$, or health education promotion.

Despite the intrinsic limitations on causality in crosssectional designs, it is valid to claim that the substantial number of individuals in the ELSA-Brasil population afforded the present study greater statistical power, contributing not just better precision in estimating AUC, but also permitting analysis adjusted for possible confounders and observation of the desired effect in different sex and age strata.

Information quality assurance and control measures were also taken at all stages of data collection ${ }^{(19)}$, minimising errors or flaws very common in multicentre studies involving large numbers of actors.

Although widely used in diagnostic studies to compare the power of different predictors, the AUC is an insufficient measure of discrimination to evaluate the predictive model completely. In addition, we used the Brier score, a robust methodology for analysis of validity ${ }^{(39)}$ and, in the present study, the values corroborated the consistency of the results, highlighting the internal validity of the anthropometric indicator tested.

In conclusion, we propose to include WHtR, which had good discriminatory power for important cardiometabolic outcomes and performed similarly to, or better than, other available indices of adiposity, as an anthropometric index in the monitoring of nutritional status of the Brazilian adult population, assuming the cut-off of 0.50 as more sensitive and indicated for actions in public health.

\section{Acknowledgements}

Acknowledgements: The authors would like to thank all ELSA-Brasil participants for their contribution to this study. Financial support: The ELSA-Brasil baseline study was supported by the Brazilian Ministry of Health (Science and Technology Department) and the Brazilian Ministry of 
Science and Technology (Financiadora de Estudos e Projetos and CNPq National Research Council; grant numbers 01060010.00 RS, 01060212.00 BA, 01060300.00 ES, 01 06 0278.00 MG, 0106 0115.00 SP, 01060071.00 RJ). The Brazilian Ministry of Health and the Brazilian Ministry of Science and Technology had no role in the design, analysis or writing of this article. Conflict of interest: None. Authorship: Contributed to the conception and planning of the study: M.C., D.C., L.O.C., R.H.G., M.C.M. and M.J.M.F. Data analysis and interpretation: M.C., J.U.B. and M.J.M.F. Prepared the manuscript: M.C. Critical review of the manuscript: M.C., D.C., L.O.C., R.H.G., M.C.M. and M.J.M.F. Ethics of buman subject participation: This study was conducted according to the guidelines laid down in the Declaration of Helsinki and all procedures involving human subjects/patients were approved by the Ethics Committee of Brazil's Escola Nacional de Saúde Pública (CAAE no. 44106915.2.1001.5240). Written informed consent was obtained from all subjects/patients.

\section{References}

1. Schmidt MI, Duncan BB, Azevedo e Silva G et al. (2011) Chronic non-communicable diseases in Brazil: burden and current challenges. Lancet 377, 1949-1961.

2. Tchernof A \& Després JP (2013) Pathophysiology of human visceral obesity: an update. Physiol Rev 93, 359-404.

3. World Health Organization (2011) Waist Circumference and Waist-Hip Ratio: Report of a WHO Expert Consultation. Geneva: WHO.

4. Langenberg C, Shipley MJ, Batty GD et al. (2005) Adult socioeconomic position and the association between height and coronary heart disease mortality: findings from 33 years of follow-up in in the Whitehall Study. Am J Public Health 95, 628-632.

5. Schneider HJ, Klotsche J, Silber S et al. (2011) Measuring abdominal obesity: effects of height on distribution of cardiometabolic risk factors risk using waist circumference and waist-to-height ratio. Diabetes Care 34, e7.

6. Sawaya AL, Leandro CG \& Waitzberg DL (2013) Baixa estatura e suas consequencias em longo prazo. In Fisiologia da Nutrição na Saúde e na Doença - Da Biologia Molecular ao Tratamento, pp. 323-338 [AL Sawaya, editor]. São Paulo: Atheneu.

7. Lee CMY, Huxley RR, Wildman RP et al. (2008) Indices of abdominal obesity are better discriminators of cardiovascular risk factors than BMI: a meta-analysis. J Clin Epidemiol 61, 646-653.

8. Ashwell M, Gunn P \& Gibson S (2012) Waist-to-height ratio is a better screening tool than waist circumference and BMI for adult cardiometabolic risk factors: systematic review and meta-analysis. Obes Rev 13, 275-286.

9. Savva SC, Lamnisos D \& Kafatos AG (2013) Predicting cardiometabolic risk: waist-to-height ratio or BMI. A metaanalysis. Diabetes Metab Syndr Obes 6, 403-419.

10. Fuchs FD, Gus M, Moreira LB et al. (2005) Anthropometric indices and the incidence of hypertension: a comparative analysis. Obes Res 13, 1515-1517.

11. Caminha TCS, Ferreira HS, Costa NS et al. (2017) Waist-toheight ratio is the best anthropometric predictor of hypertension. A population-based study with women from a state of northeast of Brazil. Medicine 96, e5874.
12. Haun DR, Pitanga FJ \& Lessa I (2009) Razão cintura/estatura comparado a outros indicadores antropométricos de obesidade como preditor de risco coronariano elevado. Rev Assoc Med Bras 55, 705-711.

13. Almeida RT, Almeida MMG \& Araújo TM (2009) Obesidade abdominal e risco cardiovascular: desempenho de indicadores antropométricos em mulheres. Arq Bras Cardiol 92, 375-380.

14. Liu Y, Tong G, Tong W et al. (2011) Can body mass index, waist circumference, waist-hip ratio and waist-height ratio predict the presence of multiple metabolic risk factors in Chinese subjects? BMC Public Health 11, 35.

15. Vasques AC, Rosado LE, Rosado GP et al. (2009) Habilidade de indicadores antropométricos e de composição corporal em identificar a resistência à insulina. Arq Bras Endocrinol Metabol 53, 72-79.

16. Pereira RA, Sichieri R \& Marins VMR (1999) Razão cintura/ quadril como preditor de hipertensão arterial. Cad Saude Publica 15, 333-344.

17. Aquino EML, Barreto SM, Bensenor IM et al. (2012) Brazilian Longitudinal Study of Adult Health (ELSA-Brasil): objectives and design. Am J Epidemiol 175, 315-324.

18. Schmidt MI, Duncan BB, Mill JG et al. (2014) Cohort profile: Longitudinal Study of Adult Health (ELSA-Brasil). Int $J$ Epidemiol 44, 68-75.

19. Schmidt MI, Griep RH, Passos VM et al. (2013) Estratégias e desenvolvimento de garantia e controle de qualidade no ELSA-Brasil. Rev Saude Publica 47, Suppl. 2, S105-S112.

20. Lohman TG, Roche AF \& Martorell R (1988) Anthropometric Standardization Reference Manual. Champaign, IL: Human Kinetics Books.

21. Mill JG, Pinto K, Griep RH et al. (2013) Aferições e exames clínicos realizados nos participantes do ELSA-Brasil. Rev Saude Publica 47, Suppl. 2, S54-S62.

22. Fedeli LG, Vidigal PG, Leite CM et al. (2013) Logística de coleta e transporte de material biológico e organização do laboratório central no ELSA-Brasil. Rev Saude Publica 47, Suppl. 2, S63-S71.

23. Expert Panel on Detection, Evaluation, and Treatment of High Blood Cholesterol in Adults (2001) Executive Summary of The Third Report of The National Cholesterol Education Program (NCEP) Expert Panel on Detection, Evaluation, And Treatment of High Blood Cholesterol In Adults (Adult Treatment Panel III). JAMA 285, 2486-2497.

24. Can AS, Bersot TP \& Gönen M (2009) Anthropometric indices and their relationship with cardiometabolic risk factors in a sample of Turkish adults. Public Health Nutr 12, 538-546.

25. Janes H \& Pepe MS (2008) Adjusting for covariates in studies of diagnostic, screening, or prognostic markers: an old concept in a new setting. Am J Epidemiol 168, 89-97.

26. Martinez EZ, Louzada-Neto F \& Pereira BB (2003) A curva ROC para testes diagnósticos. Cad Saude Colet 11, 7-31.

27. Steyerberg EW (2008) Evaluation of performance. In Clinical Prediction Models: A Practical Approach to Development, Validation, and Updating. Statistics for Biology and Health, pp. 255-280 [EW Steyerberg, editor]. New York: Springer Science \& Business Media.

28. World Health Organization (1998) Obesity: Preventing and Managing the Global Epidemic. Joint WHO/FAO Expert Consultation. WHO Technical Report Series no. 899. Geneva: WHO.

29. Ashwell M \& Hsieh SD (2005) Six reasons why the waist-toheight ratio is a rapid and effective global indicator for health risks of obesity and how its use could simplify the international public health message on obesity. Int J Food Sci Nutr 56, 303-307.

30. Perkins NJ \& Schisterman EF (2006) The inconsistency of 'optimal' cutpoints obtained using two criteria based on the receiver operating characteristic curve. Am J Epidemiol 163, 670-675. 
31. Browning LM, Hsieh SD \& Ashwell M (2010) A systematic review of waist-to-height ratio as a screening tool for the prediction of cardiovascular disease and diabetes: 0.5 could be a suitable global boundary value. Nutr Res Rev 23 , 247-269.

32. Mirmiran P, Esmaillzadeh A \& Azizi F (2004) Detection of cardiovascular risk factors by anthropometric measures in Tehranian adults: receiver operating characteristic (ROC) curve analysis. Eur J Clin Nutr 58, 1110-1118.

33. Ashwell M \& Gibson S (2016) Waist-to-height ratio as an indicator of 'early health risk': simpler and more predictive than using a 'matrix' based on BMI and waist circumference. BMJ Open 6, e010159.

34. Neamat-Allah J, Wald D, Husing A et al. (2014) Validation of anthropometric indices of adiposity against whole-body magnetic resonance imaging - a study within the German
European Prospective Investigation into Cancer and Nutrition (EPIC) cohorts. PLoS One 9, e91586.

35. Vasques AC, Rosado L, Rosado G et al. (2010) Indicadores antropométricos de resistência à insulina. Arq Bras Cardiol 95, 14-23.

36. Can AS, Yildiz EA, Samur G et al. (2010) Optimal waist: height ratio cut-off point for cardiometabolic risk factors in Turkish adults. Public Health Nutr 13, 488-495.

37. Bohr AD, Laurson K \& McQueen MB (2016) A novel cutoff for the waist-to-height ratio predicting metabolic syndrome in young American adults. BMC Public Health 16, 295.

38. Kapur A (2007) Economic analysis of diabetes care. Indian J Med Res 125, 473-482.

39. Steyerberg EW, Pencina MJ, Lingsma HF et al. (2012) Assessing the incremental value of diagnostic and prognostic markers: a review and illustration. Eur J Clin Invest 42, 216-228. 